\title{
Determinantes da Gestão do Programa Bolsa Família: análise do índice de gestão descentralizada em Minas Gerais
}

\author{
Municipal Performance in the Public Administration of \\ Programa Bolsa Familia: analysis of the decentralized \\ management index in Minas Gerais
}

\author{
Doraliza Auxiliadora Abranches Monteiro \\ Graduada em Gestão de Cooperativas. Mestranda em Administra- \\ ção Pública pela Universidade Federal de Viçosa. \\ Endereço: Rua Gomes Barbosa, 58I, CEP 36570-000, Centro, Viçosa, \\ MG, Brasil. \\ E-mail: doraliza_monteiro®yahoo.com.br

\section{Marco Aurélio Marques Ferreira} \\ Doutor em Economia Aplicada. Professor do Departamento de \\ Administração da Universidade Federal de Viçosa. \\ Endereço: Departamento de Administração - UFV Campus Uni- \\ versitário, CEP 36570-000, Viçosa, MG, Brasil. \\ E-mail: marcoaurelioळufv.br

\section{Karla Maria Damiano Teixeira} \\ PhD em Ecologia Familiar e Infantil pela Michigan State Universi- \\ ty-USA. Professora do Departamento de Economia Doméstica da \\ Universidade Federal de Viçosa. \\ Endereço: Departamento de Economia Doméstica - UFV Campus \\ Universitário, CEP 36570-000, Viçosa, MG, Brasil. \\ E-mail: kdamiano®ufv.br
}

\section{Resumo}

Este trabalho analisa os fatores que determinam a gestão do Programa Bolsa Família em Minas Gerais. O trabalho toma como referência o Índice de Gestão Descentralizada do Programa Bolsa Família (IGD), criado pelo Governo Federal no intuito de regulamentar, normatizar e incentivar a qualidade de gestão do programa, em nível municipal. Como incentivo direto, destaca-se o fato de a disponibilidade de recursos estar associada ao escore de pontuação do município, nesse índice. Foram utilizadas diversas abordagens teóricas, baseando-se na gestão e descentralização de políticas públicas para a contextualização do Programa Bolsa Família na região de estudo. 0 trabalho segue uma abordagem quanti-quali, em que foram utilizadas, como técnicas de investigação, análise de informativos do Programa Bolsa Família e estatisticamente realizou-se Análise Exploratória dos Dados (AED) e Testes de Correlação de Pearson. Dentre os principais resultados destacam-se a existência, em Minas Gerais, de municípios com baixos escores nos itens que compõem o IGD, demonstrando deficiências em diversos aspectos, tais como informações do CadÚnico e gestão das condicionalidades "saúde" e "educação". Esses fatores expõem a fragilidade da gestão pública social municipal e comprometem a eficiência do programa no Estado. Outros fatores, como o aumento da população e das famílias beneficiadas, também influenciam de forma negativa a gestão do programa, pois municípios maiores apresentaram menores escores de IGD.

Palavras-chave: Políticas Públicas; Programa Bolsa Família; Descentralização; Administração Pública. 


\section{Abstract}

This study analyzes the factors that determine the management of Programa Bolsa Família (Family Grant Program) in the State of Minas Gerais. The work uses as reference the Indice de Gestão Decentralizada (IGD - Decentralized Management Index) of Programa Bolsa Familia, created by the Federal Government in order to regulate, standardize and motivate both efficiency and quality in the program's management in the municipal level. The theoretical approaches used here were based on the management and decentralization of public policies to contextualize Programa Bolsa Familia in the region under study. The work follows a quantitative-qualitative approach, in which some of the programs' documents and institutional reports were analyzed. The statistical techniques Exploratory Data Analysis and Pearson's Correlation Tests were employed in the interpretation of the results. One of the obtained results was the existence, in Minas Gerais, of municipalities with low scores in the items composing the IGD, showing deficiencies in several aspects, such as CadÚnico (Brazil's Social Programs record system) information and management of the conditioning factors "health" and "education". These factors expose the fragility of the municipal public and social administration and hinder the program's efficiency in the State. Other factors, like the increase in the population and in the number of benefited families, also negatively affect the program's management, since the larger municipalities presented lower IGD scores.

Keywords: Public Policies; Programa Bolsa Família; Decentralization; Public Administration.

\section{Introdução}

Este estudo teve como objetivo analisar a qualidade e os fatores que determinam a gestão do Programa Bolsa Família em Minas Gerais. Procurou-se, também, investigar a eficiência da gestão pública do programa, bem como destacar sua contribuição para a melhoria da qualidade de vida e diminuição da desigualdade social no município.

O programa de transferência de renda Bolsa Família (PBF) foi instituído no ano de 2003, unificando-se os programas em curso, na época, Bolsa Escola, Bolsa Alimentação, Auxílio Gás e Cartão Alimentação. Além de transferir recursos diretamente aos beneficiários para alívio da pobreza, o Programa atua na promoção do acesso aos serviços básicos de Educação e Saúde para as famílias beneficiadas, contribuindo para o rompimento do ciclo intergeracional da pobreza (Brasil, 2007).

Em 2006, com o intuito de melhorar os procedimentos de gestão e apoiar os municípios nas atividades do Programa, o Governo Federal regulamentou o apoio financeiro aos municípios para a gestão do Bolsa Família. $\mathrm{O}$ apoio financeiro transferido mensalmente é baseado no desempenho de cada município na gestão do Programa Bolsa Família (PBF). Dessa forma, municípios que alcançarem os melhores resultados na gestão do Programa receberão mais recursos. E, para medir o desempenho das administrações municipais, foi criado o Índice de Gestão Descentralizada do Programa Bolsa Família (IGD) (Brasil, 2008a).

O IGD é um índice de qualidade da gestão que combina integridade, qualidade e atualização das informações constantes do CadÚnico ${ }^{1}$ e informações sobre os cumprimentos das condicionalidades das áreas de Educação e Saúde. Em 2007, o montante de recursos transferido durante todo o ano para os municípios, baseado no IGD, foi de R\$ 216.779.300,oo (Brasil, 2008e).

Uma das questões mais discutidas, no contexto econômico e social brasileiro, é relativa à alocação dos recursos em programas sociais (Chiechelski, 2005). Dessa forma, o estudo e a avaliação da gestão de políticas públicas podem proporcionar informações e

10 Decreto $n^{\circ}$ 6.135/o7 define o CadÚnico como uma base de dados nacional, que identifica as características sociais e econômicas das famílias brasileiras mais pobres. Ele deve ser obrigatoriamente utilizado para selecionar beneficiários e integrar os programas sociais do Governo Federal voltados para o atendimento desse público (Brasil, 20o8e). 
interpretações mais adequadas para instrumentalizar o processo de planejamento, permitindo escolher as melhores opções entre os programas e projetos a serem implantados ou propiciar avaliar os efeitos produzidos pelos que estão em andamento ou concluídos.

A gestão do Bolsa Família é realizada pela secretaria da área onde está localizado o Programa (Assistência Social, Educação, Saúde e planejamento, entre outros), de acordo com nomeação do poder executivo municipal. Essa secretaria assume a interação política entre a prefeitura, o Ministério do Desenvolvimento Social e Combate à Fome (MDS) e o governo estadual para a implementação do Bolsa Família e do Cadastro Único. Por isso, o gestor deve ter poder de decisão, de mobilização de outras instituições e de articulação e coordenação entre as áreas envolvidas na operação do Programa, como Assistência Social, Educação e Saúde para o acompanhamento dos beneficiários e a verificação das condicionalidades exigidas para a participação no Programa (Brasil, 2008b).

As questões às quais se pretenderam responder neste estudo foram: a) Quais os fatores que determinam a qualidade da gestão do Programa Bolsa Família?; b) Existe relação direta entre tamanho dos municípios, quantidade de famílias beneficiadas e gestão de programas de transferência de renda e combate à pobreza?

\section{Referencial Teórico}

\section{Gestão de Políticas Públicas}

Pode-se considerar que grande parte da atividade política dos governos se destina à tentativa de satisfazer as demandas que lhes são dirigidas pelos atores sociais ou aquelas formuladas pelos próprios agentes do sistema político, ao mesmo tempo em que articulam os apoios necessários (Rua, 2006).

Embora o campo da política pública seja amplo, abrangendo diversos atores sociais, como indivíduos, instituições, interações, ideologias e grupos de interesses, neste estudo a política é tratada como um conjunto de programas ou objetivos que tem o governo em determinada área, com consequência de fatos e decisões que implicam certa evolução ou modificação da realidade (Castanhar, 2006).

Entre as diversas opções discorridas no contexto atual, têm se destacado as políticas públicas de transferência de renda. Essa política foi introduzida no Brasil a partir dos anos 1990 e abrange vários aspectos da Administração Pública, como econômicos, sociais, assistenciais e educacionais. Por mencionar aspectos da concentração de renda e pobreza, sendo este o grande desafio para as políticas públicas e o desenvolvimento do país, o seu estudo permite desenvolver elementos que ajudam a compreender e avaliar a disseminação de outras políticas.

As desigualdades visualizadas no país vislumbram por um Estado ativo, promotor da justiça social. A escassez clama por esforços de otimização, e o quadro global competitivo requer um Estado regulador e uma gestão econômica consistente, que tem o cidadão como o foco da ação pública (Brasil, 2003). Dessa forma, temas como qualidade, eficiência e eficácia, tão utilizados na administração de empresas, têm sido frequentemente apropriados pela gestão pública. Essas transformações requerem redefinição de estratégias e capacidade do poder público em formular e implementar políticas públicas de forma eficiente, transparente, participativa e de qualidade.

O desempenho de uma organização, nesse caso a organização pública, é aceitável ou satisfatório quando os problemas dos usuários são resolvidos por meio da utilização correta dos recursos (Maximiano, 2007). Assim, eficácia é a palavra utilizada para indicar que a organização realiza seus objetivos, e Moreira (2006) a definiu como ligada ao objetivo em si, como a relação entre os resultados almejados e os previstos.

A eficiência pode ser entendida como o meio de fazer certo um processo correto de boa qualidade, em curto prazo e com o menor número de erros (Moreira, 2006). Ferreira (2007) a definiu como a capacidade ou, até mesmo, a habilidade de fazer uso mais adequado do que se tem à disposição, a fim de alcançar resultados pretendidos.

Maximiano (2007), descrevendo sobre o tema Qualidade, afirma que essa tem quer ser embutida no produto ou serviço desde o começo, a partir dos desejos e interesses dos clientes. A responsabilidade de todos pela qualidade e a garantia da qualidade dos produtos e serviços, do começo ao fim do processo, exigem um enfoque sistêmico, para integrar ações das pessoas, máquinas, informações e todos os outros recursos envolvidos na administração da qualidade.

Tal fato indica que a gestão busca assegurar eficácia, eficiência e qualidade das organizações, e unir 
esses conceitos é essencial para o cumprimento das propostas das políticas públicas. Isso de tal modo que acompanhar a implementação de programas sociais como o PBF num país como o Brasil é um grande desafio, pois esse programa demanda estrutura burocrática mínima, que associe transparência de gastos públicos aos resultados socioeconômicos de sua implantação. Portanto, a eficiência, a eficácia e a qualidade são algumas das principais medidas para se avaliar uma boa administração, já que quase sempre os recursos são limitados ou escassos.

Aponta-se, portanto, que para averiguar a gestão do Programa Bolsa Família, é necessário um bom acompanhamento do CadÚnico e das Condicionalidades, já que estas estão diretamente atreladas à eficiência, eficácia e qualidade do Programa e possuem parâmetros para avaliar a sua gestão.

\section{Descentralização de Políticas Públicas}

Uma organização é descentralizada quando o poder de decisão está distribuído, e a autoridade é realizada por meio do processo de delegação (Maximiano, 2007). A descentralização estimula a autonomia e possibilita o melhor aproveitamento do potencial das pessoas, de modo que permite criatividade na busca de soluções e agilidade na tomada de decisões.

A descentralização é um acontecimento observado tanto nas organizações privadas quanto públicas. Sob a influência da administração de empresas, começaram a se fazer sentir na administração pública as ideias de descentralização e de flexibilização, ganhando espaço em todos os governos (Bresser-Pereira e Spink, 2006).

Essa reforma administrativa ganhou força a partir dos anos 1970, quando teve início a crise do Estado e da burocracia. Nos anos 1980, iniciou-se uma grande revolução na administração pública dos países centrais em direção a uma administração pública gerencial (Bresser-Pereira e Spink, 2006).

Com a descentralização da administração pública, as prefeituras, por exemplo, têm assumido cada vez mais funções e procurado empregar profissionais para traçar suas políticas sociais e gerenciar sua máquina administrativa (UNIGUAÇU, 2008).

O que se tem observado é uma redistribuição das responsabilidades referentes às ações e serviços entre vários níveis de governo (Federal, Estadual e Municipal), resultado de uma redefinição das atribuições e do reforço do poder municipal (municipalização), aumentando, assim, suas tarefas em várias áreas, como Saúde e Educação. A municipalização permitiu a cada município conhecer seus problemas e agir de acordo com as suas necessidades, responsabilizando-se pela gestão dos serviços básicos.

Segundo Ortiz (2007), são diversas as razões para a descentralização: a dimensão continental do país, as diferenças regionais e uma enorme quantidade de municípios, mais de 5.50o, sendo a maioria de pequeno porte.

Desde a criação do Bolsa Família, em 2003, até o ano de 2005, a gestão desse Programa era feita pela Secretaria Nacional de Renda e Cidadania (SENARC), que realizava as atividades de bloqueio, desbloqueio, cancelamento de benefícios e a gestão a partir da solicitação do prefeito ou do gestor municipal do Bolsa Família (Brasil, 2008c).

A partir de 2005, o MDS promoveu a descentralização da Gestão de Benefícios do Programa Bolsa Família, permitindo aos gestores municipais do Programa administrar, em seu próprio município, a transferência de renda às famílias beneficiadas. Com essa ação, os municípios ganharam maiores responsabilidades, assim como passaram a lograr recursos humanos técnicos e qualificados para o novo esboço de atividades na gestão do Programa.

A gestão descentralizada do Programa Bolsa Família para o MDS é uma prática regular e adequada das ações relacionadas ao cumprimento dos compromissos assumidos no Termo de Adesão ao PBF, bem como das atribuições dos entes locais constantes dos demais instrumentos legais que regem o PBF, sendo esta mensurada por indicadores de qualidade da gestão que compõe o IGD (Brasil, 2008e). Assim, o Gestor Municipal do Programa Bolsa Família tem como principais funções: assumir a interlocução política entre a prefeitura, o MDS e o Estado para a implementação do PBF e do Cadastro Único; coordenar a relação entre as Secretarias de Assistência Social, Educação e Saúde para o acompanhamento dos beneficiários do PBF e a verificação das condicionalidades; coordenar a execução dos recursos transferidos pelo Governo Federal para o Programa Bolsa Família nos municípios; coordenar a interlocução com outras secretarias e órgãos vinculados ao próprio governo municipal, do Estado e do Governo Federal e, ainda, com entidades não governamentais (Brasil, 20o8b). 
Com a transferência da administração para os gestores municipais, ocorreu o processo de descentralização das decisões e da delegação das funções, criando, portanto, o IGD, que mede a qualidade dessa gestão descentralizada.

\section{Metodologia}

Esta seção está dividida em quatro partes, sendo a primeira fonte de dados, amostra e área de estudo; a segunda, métodos de pesquisa utilizados; a terceira, composição do IGD e, a quarta, interpretação do IGD.

Foi realizada uma Análise Exploratória de Dados (AED), que aborda o estudo e a descrição das características de um conjunto de dados, com os objetivos de compreender, descrever e resumir o comportamento dos fenômenos e eventos numéricos.

A AED compõe a análise de medidas de tendência central como média, mediana e moda, e de medidas de dispersão como o desvio-padrão, a amplitude e a assimetria, que visam verificar como os dados estão distribuídos e concentrados, além de observar a presença de outliers.

E, para constatar a intensidade da relação entre conjuntos de valores quantitativos emparelhados, foi realizado o cálculo do coeficiente de correlação linear - Correlação de Pearson, apresentado na equação 1.

$r_{x y}=\frac{\operatorname{cov}(x y)}{\sqrt{\operatorname{var}(x) \operatorname{var}(y)}}$

Em que:

= coeficiente de correlação de Pearson;

cov = covariância amostral;

var = variância amostral.

Na análise do coeficiente de correlação, dois fatores devem ser analisados: a intensidade da correlação e a direção da correlação. Assim, a determinação das correlações permite excluir aquelas variáveis que não admitem relações com as demais, bem como verificar a mensuração da similaridade ou associação entre as variáveis.

Conforme descrito na Figura 1, os valores do coeficiente de correlação podem variar de o a 1, em que o significa correlação neutra, e 1 significa correlação plena. O sinal indica o sentido da correlação. Assim, negativo significa associação inversa entre o par de variáveis e, positivo, associação na mesma direção. A média dos produtos dos desvios em cada par de pontos de dados é utilizada para determinar a relação entre dois conjuntos de dados.

\section{Figura I - Descrição dos coeficientes de correlação}

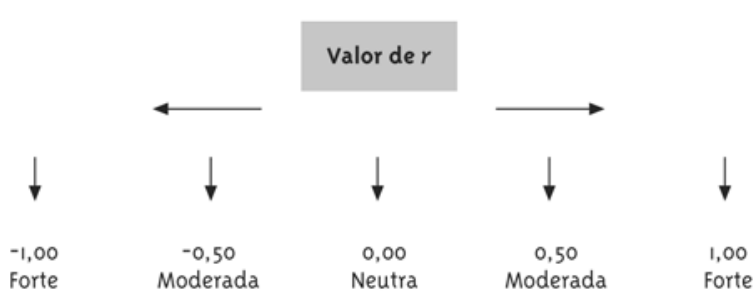

Fonte: Construção dos autores.

\section{Fonte de dados, amostra e área de estudo}

O estudo foi constituído com base em dados secundários por meio de informações e publicações do Governo Federal/Ministério de Desenvolvimento Social e Combate à Fome - Programa Bolsa Família/IGD e Instituto Brasileiro de Geografia e Estatística (IBGE).

A amostra foi composta de 296 municípios de diferentes mesorregiões mineiras, os quais foram selecionados aleatoriamente com base em toda a população.

Após uma Análise Exploratória dos Dados (AED), conforme proposto por Triola (2005) e Hair e colaboradores (2005), optou-se pela exclusão de municípios que possuíam alta população, como Belo Horizonte (2.412.937), Contagem (6o8.650), Uberlândia (6o8.369), Juiz de Fora (513.348), Betim (415.098) e Governador Valadares (260.396), por serem considerados Outliers (valores extremos), sendo a medida de tendência central, média, sensível a valores extremos. A manutenção desses Outliers em estudo eleva demasiadamente a média da população mineira, mascarando a realidade de que cerca de $80 \%$ dos municípios de Minas Gerais possuem população de até 20.000 habitantes e 97\% até 100.000 pessoas (IBGE, 2007a). Ressalta-se que essa também é uma realidade brasileira, ou seja, cerca de $71 \%$ dos municípios do país possuem até 20.000 habitantes (Brasil, 2007).

Para fins de classificação, a pesquisa considerou os municípios por porte de acordo com o MDS. Os de pe- 
queno porte são aqueles com população de até 20.000 habitantes, os de médio porte são aqueles com população entre 20.001 e 100.00o, e os de grande porte são aqueles municípios com população superior a 100.001 habitantes. De acordo com os dados agrupados a seguir, todas as mesorregiões mineiras estão representadas na pesquisa, assim como municípios de diferentes portes (Tabela 1).

\section{Tabela I - Participação dos municípios no estudo segundo a mesorregião geográfica e o porte}

\begin{tabular}{|c|c|c|c|c|c|c|c|}
\hline \multicolumn{2}{|c|}{ Mesorregião } & \multirow{2}{*}{$\begin{array}{c}\text { Freq. } \\
\text { II }\end{array}$} & \multirow{2}{*}{$\begin{array}{l}(\%) \\
3,7\end{array}$} & \multicolumn{2}{|c|}{ Portes Populacionais } & \multirow{2}{*}{$\begin{array}{l}\text { Freq. } \\
240 \\
\end{array}$} & \multirow{2}{*}{$\begin{array}{l}(\%) \\
81,1\end{array}$} \\
\hline 1 & Campo das Vertentes & & & 1 & Até 20.000 hab. (pequeno) & & \\
\hline 2 & Central Mineira & II & 3,7 & 2 & 20.001 a 100.000 hab. (médio) & 51 & 17,2 \\
\hline 3 & Jequitinhonha & 20 & 6,8 & 3 & Maior que 100.00। hab. (grande) & 5 & 1,7 \\
\hline 4 & Metropolitana de Belo Horizonte & 37 & 12,5 & & Total & 296 & 100,0 \\
\hline 5 & Noroeste de Minas & 7 & 2,4 & & & & \\
\hline 6 & Norte de Minas & 40 & 13,5 & & & & \\
\hline 7 & Oeste de Minas & 15 & 5,1 & & & & \\
\hline 8 & Sul e Sudoeste de Minas & 55 & 18,6 & & & & \\
\hline 9 & Triângulo Mineiro e Alto Paranaíba & 24 & 8,1 & & & & \\
\hline 10 & Vale do Mucuri & 9 & 3,0 & & & & \\
\hline 11 & Vale do Rio Doce & 23 & 7,8 & & & & \\
\hline \multirow[t]{2}{*}{12} & Zona da Mata & 44 & 14,9 & & & & \\
\hline & Total & 296 & 100,0 & & & & \\
\hline
\end{tabular}

Fonte: Resultados da pesquisa.

As regiões mais representadas no estudo foram: Sul e Sudoeste de Minas (18,6\%), Zona da Mata (14,9\%), Norte de Minas (13,5\%) e Metropolitana de Belo Horizonte $(12,5 \%)$, sendo estas, também, as mesorregiões com maior numero de municípios do Estado. No entanto, as regiões menos representadas também são aquelas que possuem menos municípios nas regiões, sendo elas Noroeste de Minas (2,4\%), Vale do Mucuri (3\%), Central Mineira (3,7\%) e Campo das Vertentes (3,7\%).

A escolha de Minas Gerais se justifica por ser o Estado que mais se destaca pelas disparidades regionais. Coexistem em mesmo escopo territorial regiões dinâmicas e modernas em contraste com regiões atrasadas e estagnadas. Vale destacar também que Minas Gerais é o maior Estado da região Sudeste, quarto do país em área, segundo em população e possui a terceira economia do país, ficando abaixo de São Paulo e Rio de Janeiro. Possui uma área de 586.528,2936 km², 19 milhões de habitantes que se distribuem em $853 \mathrm{mu}$ nicípios; em 2003, o PIB foi de R\$ 114.544.822 e o PIB per capita de R\$ 7.790,00 (IBGE, 2007b). Os municípios mineiros são 51,2\% daqueles da região Sudeste e 15,5\% de todo o Brasil.
O Estado de Minas Gerais recebe do Ministério do Desenvolvimento Social e Combate à Fome (MDS), por ano, R\$ 2,36 bilhões para execução de programas sociais. As ações nas áreas de Transferência de Renda, Assistência Social e Segurança Alimentar beneficiam 6,9 milhões de pessoas. O Programa Bolsa Família transferiu, por mês, em 2007, R\$ 75,5 milhões para 1,1 milhão de famílias mineiras (Brasil, 2008f).

\section{Métodos de Pesquisa}

As variáveis utilizadas pelo estudo foram: População, Recursos Transferidos no Mês para Apoio à Gestão (R\$), Teto de Recursos para Apoio à Gestão (R\$), Total de Famílias Beneficiadas pelos Programas, Índice de Validade dos Cadastros, Índice de Atualização de Cadastro, Índice de Condicionalidade de Educação, Índice de Condicionalidade de Saúde e Índice de Gestão Descentralizada do Mês (IGD).

As variáveis foram escolhidas com base na composição do IGD, bem como nas informações que o Ministério do Desenvolvimento Social e Combate à Fome (MDS), Bolsa Família Informa e o Instituto Brasileiro de Geografia e Estatística (IBGE) possuíam sobre o 
Programa Bolsa Família e os municípios do Estado de Minas Gerais.

Os dados foram operacionalizados utilizando-se o programa "Statistic Package for Social Science" (SPSS) 15.0, e, posteriormente, analisados de forma quantitativa e qualitativa.

\section{Índice de Gestão Descentralizada (IGD)}

O IGD tem como propósito acompanhar a gestão do Programa Bolsa Família, bem como medir a qualidade desta. É um indicador sintético, criado por força da Portaria GM/MDS n. ${ }^{0}$ 148, de 2006, com o objetivo de apoiar financeiramente os municípios do Programa Bolsa Família, com base na qualidade da gestão do Programa. 0 índice é composto pela média aritmética do Indicador do CadÚnico e do Indicador de condicionalidades, conforme destacado na equação 1 (Brasil, 2007).

$\mathrm{IGD}=\frac{(\text { ICadastroÚnico }+ \text { ICondicionalidades })}{2}$

Em que:

IGD: Índice de Gestão Descentralizada;

Indicador do CadÚnico: média entre a taxa de validação de cadastros e a taxa de atualização cadastral;

Indicador de Condicionalidades: média entre a taxa de crianças com informações de frequência escolar e a taxa de famílias com acompanhamento da agenda de saúde.

De acordo com o MDS/Senarc (Brasil, 2007), esses componentes foram priorizados, levando-se em conta dois aspectos. 0 primeiro se refere à qualidade das informações do cadastro, pois dados imprecisos ou desatualizados no CadÚnico podem ocasionar erros de focalização e pagamentos indevidos, dificultando, ou, até mesmo, impossibilitando o acompanhamento das condicionalidades e tornando mais complexas as atividades de gestão de benefícios. 0 segundo diz respeito ao monitoramento das condicionalidades, atividade que indica o esforço do município em garantir a oferta dos serviços de Saúde e Educação e em acompanhar as famílias do PBF não só informando se elas utilizam ou não esses serviços, mas também conhecendo e acompanhando as que não o fazem.

Para receber os recursos financeiros do IGD, o município deve cumprir três condições: ter aderido ao Programa Bolsa Família nos termos da Portaria GM/MDS $n^{0}$. 246/o5; ser habilitado na gestão da Assistência Social; e atingir, pelo menos, o,4 no valor do IGD.
Os recursos transferidos no mês para apoio à gestão são o resultado da multiplicação do IGD do município (calculado segundo as quatro variáveis anteriormente apresentadas) pelo valor de referência de $\mathrm{R} \$ 2,50$ (dois reais e cinquenta centavos), e, desse produto, pelo número de beneficiários do Bolsa Família no município. Isso significa que os municípios com IGD igual a " 1 " recebem R\$ 2,50 por família beneficiária, a cada mês. Além disso, o valor é calculado em dobro para até 200 famílias em cada município, de forma a favorecer os pequenos municípios. Os valores transferidos são calculados, portanto, de acordo com a seguinte fórmula:

Repasse mensal $=$

[ICD $\times R \$ 2,50 \times 200 \times 2]+\left[I C D \times R \$ 2,50 \times\left(n^{\circ}\right.\right.$ de famílias - 200)]

Ressalta-se que, quanto maior o valor do IGD, maior também o valor do recurso transferido para o município. Por meio da construção do IGD, o MDS incentiva o aprimoramento da qualidade da gestão do Programa Bolsa Família em nível local e contribui para que os municípios executem as ações que estão sob a sua responsabilidade (Brasil, 2008d).

De acordo com a Portaria $\mathrm{n}^{\circ} 148$, artigo $2^{\circ}$, os recursos transferidos devem ser utilizados nas seguintes atividades: gestão de condicionalidades; gestão de benefícios; acompanhamento das famílias beneficiárias; cadastramento de novas famílias, atualização e revisão dos dados contidos no CadÚnico; atendimento às demandas relacionadas à fiscalização do Programa Bolsa Família; e implementação de programas complementares ao Programa nas áreas de: a) alfabetização e Educação de Jovens e Adultos; b) capacitação profissional; c) geração de trabalho e renda; d) acesso ao microcrédito produtivo orientado; e e) desenvolvimento comunitário e territorial, entre outras.

\section{Análise do IGD}

Conforme abordado, o IGD é um índice de qualidade da gestão do Programa Bolsa Família que combina informações sobre validade e atualização de cadastros e informações das condicionalidades Saúde e Educação.

Não há menção nos informes e publicações do MDS e Bolsa Família de sugestões de corte para a análise do IGD, apenas impõe-se que, para o recebimento do recurso financeiro, os municípios devem possuir um índice mínimo de o,4. Dessa forma, propôs-se nesse estudo elencar um escala de qualidade com escores 
que permeiam de Ruim a Excelente, sendo eles de o,40 a 1. Todavia, os resultados podem assumir valores inferiores a o,40, e, pelo fato de o valor mínimo para receber os recursos ser esse, optou-se por ser o escore mínimo na escala, para avaliar a situação do município na gestão do PBF (Figura 1).

\section{Figura I - Interpretação do IGD.}

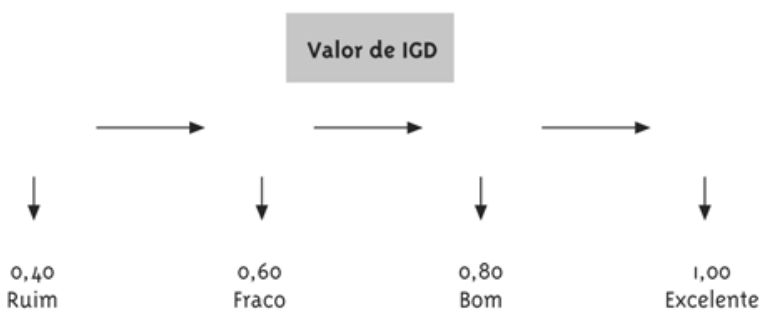

Fonte: Construção dos autores.

\section{Resultados e Discussão}

\section{Fatores determinantes do ICD}

Percebe-se que a diferença de magnitude entre os municípios que compõem a amostra reflete a realidade nacional, uma vez que 70\% dos municípios brasileiros têm população de até 20.0oo habitantes. A média da população é de 15.961,47, e, embora haja alto desviopadrão (maior que a média), ela é representativa, já que cerca de $80 \%$ da amostra possuía municípios de até 20.0oo habitantes.

A análise dos dados indicou haver apenas um município que não recebeu recursos para apoio à gestão, devido ao não alcance de, pelo menos, o,4 no valor do IGD. $O$ máximo de recursos foi de R\$ 13.856,25, e a média, de R\$ 2.099,28 por município. Ressalta-se que $74 \%$ do teto de recursos para apoio à gestão estão sendo repassados, já que a média do IGD no Estado foi de o,74 (Tabela 3). Em pesquisa realizada pelo MDS/ Senarc (Brasil, 2007), verificou-se que os recursos repassados para os municípios do IGD são utilizados para melhorar a estrutura de gestão do PBF. De modo geral, eles investiam em aquisição de computadores, material de consumo, melhoria do local de atendimento dos beneficiários, aquisição de móveis, capacitação e contratação de recursos humanos. Acredita-se que o investimento realizado esteja minimizando as dificuldades advindas da falta de estrutura adequada dos municípios para implementar as ações necessárias para a gestão descentralizada ${ }^{2}$.

Entre as famílias beneficiadas por programas sociais, cerca de $97 \%$ estão vinculadas ao PBF, e ainda há famílias beneficiadas pelos programas Bolsa Escola,

\section{Tabela 2 - Estatística descritiva das variáveis empregadas no estudo}

\begin{tabular}{l|c|c|c|c|c|c} 
Variável & Mín. & Máx. & Méd. & Desv.-pad. & Ass. & Curt. \\
\hline População & 871 & 148.075 & $15.961,47$ & $22.968,19$ & 3,27 & 11,92 \\
\hline Recursos transferidos no mês para apoio à gestão (R\$) & 0 & $13.856,25$ & $2.099,28$ & $1.830,49$ & 2,36 & 7,89 \\
\hline Teto de recursos para apoio à gestão (R\$) & 290 & $18.475,00$ & $2.988,11$ & $2.579,41$ & 2,48 & 7,93 \\
\hline Número de famílias beneficiadas do Bolsa Família & 44 & 7.424 & $1.014,31$ & $1.056,36$ & 2,39 & 7,56 \\
\hline Número de famílias beneficiadas do Bolsa Escola & 0 & 27 & 0,61 & 2,03 & 9,11 & 104,75 \\
\hline Número de famílias beneficiadas do Bolsa Alimentação & 0 & 2 & 0,01 & 0,14 & 11,64 & 145,70 \\
\hline Número de famílias beneficiadas do Auxílio Gás & 0 & 656 & 43,77 & 65,48 & 3,98 & 26,89 \\
\hline Número de famílias beneficiadas do Cartão Alimentação & 0 & 115 & 3,97 & 13,07 & 5,06 & 30,49 \\
\hline Total de famílias beneficiadas pelos Programas & 45 & 7.629 & $1.062,67$ & $1.112,05$ & 2,40 & 7,53 \\
\hline $\begin{array}{l}\text { Recursos relativos por família transferidos no mês para } \\
\text { apoio à gestão (R\$) }\end{array}$ & 0 & 4,85 & 2,35 & 0,83 & $-0,03$ & 1,35 \\
\hline
\end{tabular}

Fonte: Resultados da pesquisa.

2 As principais dificuldades elencadas para a gestão do PBF dos municípios brasileiros, de acordo com a pesquisa do MDS/Senarc (Brasil, 2007), foram: insuficiência de recursos humanos, dificuldade para operação dos sistemas computacionais, espaço físico insuficiente e equipe técnica com baixa qualificação, entre outras. Para saber mais sobre a pesquisa Análise da Pesquisa sobre Gestão Descentralizada do Programa Bolsa Família, ver: <http://www.mds.gov.br/bolsafamilia/menu_superior/manuais-e-publicacoes-1>. 
Bolsa Alimentação, Auxílio Gás e Cartão Alimentação, mas, de acordo com o MDS, a tendência é que haja, a cada ano, a diminuição e a incorporação desses programas somente ao PBF. A média de famílias beneficiadas por programas vinculados ao PBF, em Minas Gerais, é de cerca de 1.062 por município.

A média de recursos, por família, transferidos no mês de outubro de 2007 para apoio à gestão em Minas Gerais foi de R\$ 2,35, e o desvio, de R\$ o,83. Mas houve municípios, como Conceição das Pedras (Famílias Beneficiadas $=166$ ) e Serra da Saudade (Famílias Beneficiadas $=45$ ), que receberam valores acima da média, R\$ 4,85 e R\$ 4,17, respectivamente. Ressalta-se que são pequenos municípios, pois, de acordo com os critérios do IGD, o valor é calculado em dobro para até
200 famílias em cada município, de forma a favorecer os pequenos municípios.

À exceção da variável "Recursos Relativos por Família Transferidos no Mês para Apoio à Gestão”, todas as outras variáveis do estudo apresentaram assimetria positiva. $\mathrm{O}$ que demonstra, de acordo com Hair e colaboradores (2005), valores concentrados na extremidade inferior da tabela de distribuição, além da influência de outliers positivos.

Em todas as variáveis do estudo, o coeficiente de curtose é positivo, sendo, portanto, a distribuição leptocúrtica (mais aguda e em forma de cume).

Na Tabela 3, apresentam-se as variáveis empregadas na formação do IGD, assim como suas estatísticas descritivas.

Tabela 3 - Estatística descritiva das variáveis empregadas na formação do Índice de Gestão Descentralizada - IGD

\begin{tabular}{l|c|c|c|c|c|c} 
Variável & Mín. & Máx. & Méd. & Des.-Pad. & Ass. & Curt. \\
Índice de Validade dos Cadastros & 0,23 & 1,00 & 0,78 & 0,17 & $-0,39$ & $-0,56$ \\
\hline Índice de Atualização de Cadastro & 0,31 & 0,99 & 0,82 & 0,13 & $-1,33$ & 1,82 \\
\hline Índice de Condicionalidade de Educação & 0,09 & 1,00 & 0,86 & 0,11 & $-2,14$ & 8,65 \\
\hline Índice de Condicionalidade de Saúde & 0 & 1,00 & 0,48 & 0,31 & $-0,02$ & $-1,20$ \\
\hline Índice de Gestão Descentralizada do Mês (IGD) & 0,39 & 0,97 & 0,74 & 0,10 & $-0,12$ & $-0,02$ \\
\hline
\end{tabular}

Fonte: Resultados da pesquisa.

As variáveis "Índice de Validade de Cadastro" e "Índice de Atualização de Cadastro" (Indicador CadÚnico) apresentaram médias de o,78 e o,82, respectivamente, verificando-se municípios com até o,23 e o,31. Isso evidencia que estão ocorrendo problemas em relação à qualidade das informações no cadastro, principalmente no quesito Validade. Ressalta-se que dados imprecisos ou desatualizados podem ocasionar erros de focalização e pagamentos indevidos, dificultando, ou, até mesmo, impossibilitando o acompanhamento das condicionalidades e tornando mais complexas as atividades de gestão de benefícios. Mas há também municípios com esses índices em boa situação, o que demonstra organização nos cadastros das famílias.

A "Condicionalidade de Saúde" apresenta a menor média $(o, 48)$ e o maior desvio-padrão $(0,31)$, resultante da relativa dispersão dos dados em torno da média (dispersão grande, pois o desvio é maior que a metade da média), enfraquecendo, assim, as inferências de tendência central, fator que tem determinado a diminuição do IGD e representa baixa taxa de famílias com acompanhamento da agenda de saúde entre as famílias beneficiadas.

Esse fator pode indicar falhas no monitoramento dessa condicionalidade, o que indica que o município não está garantindo a oferta desse serviço, ou não está ocorrendo integração das ações do gestor do PBF com a área da saúde do município, limitando, dessa forma, o cumprimento dos objetivos do Programa, que são a redução da vulnerabilidade social e a melhora da qualidade de vida da população atendida pelo PBF.

Conforme mencionado, $50 \%$ dos repasses do IGD são consequência do desempenho no acompanhamento das condicionalidades, e um alto IGD - que significa mais recursos a serem utilizados na gestão do PBF - é diretamente proporcional ao registro das informações de acompanhamento também nas áreas de Saúde (prénatal, aleitamento materno, alimentação e vacinação) e Educação (frequência escolar). 
Os índices mínimos nas condicionalidades Educação e Saúde são o,og e o, e o máximo é 1 em ambos. Observa-se que a amplitude (diferença entre o maior e o menor valor) é grande, evidenciando que há municípios com boa gestão no quesito "condicionalidades" e também municípios com péssima gestão nesse quesito.

De acordo com o MDS (Brasil, 2008e), o objetivo das condicionalidades é ampliar o acesso dos cidadãos aos seus direitos sociais básicos, em especial os relativos à Saúde e à Educação. $\mathrm{O}$ acompanhamento do cumprimento das condicionalidades é muito importante, porque permite a identificação das famílias que estão com problemas de acesso a esses serviços, não só informando se elas os utilizam ou não, mas também conhecendo e acompanhando as que não o fazem. Esses fatores indicaram que, em Minas Gerais, têm ocorrido lacunas nesses quesitos, seja com acesso ao serviço, seja com o registro das informações, embora o "Índice de Condicionalidade de Educação" tenha alcançado a melhor média dos componentes do IGD.

Fator agravante é que, embora a condicionalidade "Saúde" tenha tido desempenho ruim para o IGD, a despesa com saúde teve crescimento no país pela exigência da emenda constitucional $n^{0}$. 29/200o, que obriga os municípios e estados a aplicarem, no mínimo, $15 \%$ de suas receitas próprias em saúde (Lavinas, 2007). Essa questão exalta ainda mais as nuances existentes no sistema de saúde conjugadas com as atividades do PBF em Minas Gerais, já que a oferta de serviços públicos de qualidade e informações precisas é um objetivo para a superação das desigualdades e ampliação de oportunidades.

Estudos de Lavinas (2007) e Pochmann (2007) demonstraram que a despesa com Educação, voltada sobremaneira para o Ensino Fundamental, pré-escola, creche e alfabetização, de importância estratégica para os programas de transferência de renda condicionada à frequência escolar, diminuiu nos municípios. Em contrapartida, no ano de 2006 houve aumento de o,9\% no número total de estudantes em relação ao ano de 2005 , principalmente no grupo de 7 a 14 anos de idade, onde a presença na escola foi maior (IBGE, 2006), ressaltandose que é nessa faixa de idade que há focalização das principais políticas de transferência de renda.

Isso evidencia que o Estado está exercendo parcialmente seu papel, pois incentiva a participação escolar por meio dos programas sociais condicionados à educação, mas não proporciona incentivos e outros mecanismos de inclusão, como melhoria na infraestrutura das escolas ou qualidade dos docentes.

A assimetria das variáveis que compõem o IGD é negativa, ressaltando-se que, embora haja maior concentração das variáveis à direita, existe influência de outliers de menor valor.

Os valores negativos encontrados para a curtose nas variáveis Índice de Validade dos Cadastros, Índice de Condicionalidade de Saúde e Índice de Gestão Descentralizada do Mês (IGD) significam que a distribuição é platicúrtica (plana). Desse modo, os valores estão relativamente dispersos, distanciando-se lentamente da média. Os demais, Índice de Atualização de Cadastro e Índice de Condicionalidade de Educação, possuem distribuição leptocúrtica (mais aguda e em forma de cume), demonstrando forte concentração em torno da média.

Essas diferenças abrem espaço a uma discussão importante, qual seja: a média por si só representa aspecto muito simplista, em análises de indicadores voltados à análise de políticas públicas e sociais. Como exemplo, toma-se a medida do Índice de Condicionalidade de Saúde, que tem média de o,48, mas, ao mesmo tempo, tem assimetria à esquerda (municípios de baixíssimo escore) e distribuição achatada, representado alta heterogeneidade. Fatos que exigem uma análise multidimensional, visando abordar todos os fatores relacionados ao comportamento das variáveis em questão, antes de emitir qualquer parecer determinístico.

Nesse sentido, houve municípios que não atingiram o escore mínimo para receber recursos do $\operatorname{IGD}(0,40)$, estando em péssima situação na gestão; e também municípios com escores de "bom" a "excelente", superiores a o,81, na qualidade da gestão do Programa Bolsa Família, totalizando $25,4 \%$ da amostra. A média $(0,74)$ está contida entre os escores "fraco" e "bom", sendo esta também realidade de $68,9 \%$ dos municípios estudados (Tabela 4).

\section{Tabela 4 - Frequência de municípios por escore de IGD}

\begin{tabular}{l|c|c} 
Escores de IGD & Frequência & Percentual (\%) \\
\hline Até 0,40 & 1 & 0,3 \\
\hline 0,41 a 0,60 & 16 & 5,4 \\
\hline 0,61 a 0,80 & 204 & 68,9 \\
\hline 0,8 । a 1,00 & 75 & 25,4 \\
\hline Total & 296 & 100,0 \\
\hline
\end{tabular}

Fonte: Resultados da pesquisa. 
Foram realizados testes de correlação para analisar outros fatores, além daqueles que compõem o IGD, que também influenciam as variações deste.

\section{Associação entre as variáveis do estudo 3}

O cálculo do coeficiente de correlação demonstrou que existe associação entre o IGD e as seguintes variáveis: população, total de famílias beneficiadas e teto de recursos para apoio à gestão. Todavia, conforme pode ser observado na Tabela 4, o sinal negativo da correlação significa associação linear inversa entre o par de variáveis. Desse modo, os dados evidenciam a existência de correlação negativa entre o IGD e as variáveis, sendo as medidas significativas a $5 \%$ e $1 \%$ de probabilidade, pelo teste "T".

Os resultados indicaram haver relação inversa e fraca entre o tamanho da população e o valor do IGD. Daí surge a seguinte questão: municípios maiores têm maior dificuldade em gerir programas de transferência de renda e combate à pobreza? Este estudo indicou que há associação, mas não se pode concluir que a resposta é positiva. Assim, o que se aponta, baseado nos resultados, é que há municípios que apresentam fragilidades em gerir o Programa Bolsa Família, e isso se apresenta também em maiores municípios, talvez pelas dificuldades na focalização da política pública e pelo acompanhamento das famílias. Existem também outros fatores não explorados diretamente no estudo, uma vez que é de conhecimento público que as maiores cidades sofrem, em geral, mais intensivamente de mazelas sociais, fruto do crescimento desordenado, o que dificulta, inclusive, o acesso às áreas de risco e a atualização dos próprios cadastros sociais.

Dessa forma, a dificuldade de gestão abre espaço para vicissitudes presentes na gestão de programas de políticas públicas (um exemplo é a fraude), entretanto, esse não é o escopo deste trabalho, embora seja importante destacar os pontos de relevância.

\section{Tabela 5 - Associação entre IGD e variáveis utilizadas no estudo em Minas Gerais}

\begin{tabular}{l|l|l}
\hline Variáveis & Coef. de correlação & Significância \\
\hline População & $-0,144$ & $0,013^{*}$ \\
\hline Total de famílias beneficiadas pelos programas & $-0,138$ & $0,017^{*}$ \\
\hline Teto de recursos para apoio à gestão (R\$) & $-0,158$ & $0,006^{* *}$ \\
\hline
\end{tabular}

Nota: *Significativo a $5 \%$.

${ }^{* *}$ Significativo a $1 \%$.

Fonte: Resultados da pesquisa.

Vale ressaltar, ainda, que o mesmo ocorre com o total de famílias beneficiadas por programas e com o teto de apoio à gestão dos recursos. Isso permite inferir pela relação negativa entre IGD e o aumento de famílias beneficiadas, o consequente aumento do teto de recursos e a diminuição da qualidade da gestão do PBF.

Esses fatores demonstram que: quanto mais beneficiários, maiores são as responsabilidades, aumentando, assim, as tarefas dos municípios em várias áreas, o que dificulta a coordenação e articulação, ou, até mesmo, a integração entre as Secretarias de Assistência Social, Educação e Saúde, no acompanhamento dos beneficiários do Programa e verificação das condicionalidades, debilitando, desse modo, a gestão e a operacionalização do Programa. Assim, quanto mais complexa for uma organização, mais difícil será atingir a coordenação e o controle da gestão, principalmente pelo fato de que as políticas públicas são implementadas, sobretudo, através de redes de agentes públicos e de um campo interorganizacional (Silva e Melo, 200o).

Nessa perspectiva, o tamanho dos municípios e a quantidade de beneficiários afetam a gestão de políticas públicas, bem como a eficiência e a qualidade desta. Portanto, acredita-se que, além de os componentes do IGD serem importantes para a gestão do Programa Bolsa Família, o aumento da população e das famílias beneficiárias também influencia a gestão do Programa, de forma negativa, na variação do índice.

3 Para saber mais, ver Hair e colaboradores (2005) e Triola (2005). 


\section{Conclusão}

A efetividade dos programas de transferência de renda está diretamente relacionada ao atendimento às condicionalidades instituídas pelo poder executivo, no intuito de garantir a sustentabilidade das ações e propiciar a manutenção das conquistas sociais, sejam quais forem suas dimensões, a médio e longo prazos. Dessa forma, a integração das ações do gestor do Bolsa Família com as áreas de Saúde e Educação no município garante o cumprimento dos objetivos do Programa e depõe a favor de sua efetividade social.

Dentre os aspectos gerencias do Programa, podese observar o amplo atendimento do Programa Bolsa Família, presente na quase totalidade das famílias que recebem algum benefício social. Entretanto, foi observado, também, beneficiários dos programas Bolsa Escola, Bolsa Alimentação e Auxílio Gás demonstrando que a incorporação ainda não foi plenamente atingida. As dispersões em torno do atendimento às condicionalidades destacam a existência de limitações em relação à qualidade das informações no cadastro, principalmente no quesito Validade. Ressalta-se que dados imprecisos ou desatualizados podem ocasionar erros de localização e pagamentos indevidos, dificultando, ou, até mesmo, impossibilitando o acompanhamento das condicionalidades e tornando mais complexas as atividades de gestão de benefícios. 0 estudo revelou outras importantes na gestão do PBF em Minas Gerais. Por um lado, a descentralização do sistema de gestão dos benefícios permitiu aos gestores municipais desenvolverem, de forma mais autônoma, racional e efetiva, as atividades de gestão do Programa Bolsa Família e dos programas remanescentes; por outro lado, realçou as lacunas do CadÚnico e das Condicionalidades, principalmente referentes à gestão da condicionalidade "Saúde" e da interação desses fatores com as outras Secretarias, comprometendo a eficiência dessas políticas.

O IGD é uma forma de incentivar a qualidade e eficiência da gestão do PBF. Dessa forma, quem realizar satisfatoriamente o acompanhamento das condicionalidades receberá apoio financeiro do MDS. Embora esse apoio seja interessante financeiramente e importante para os objetivos do Programa, visualizouse que, em Minas Gerais, existe um número expressivo de municípios que não respondem satisfatoriamente às exigências de desempenho no IGD, comprometendo, assim, a qualidade e eficiência da gestão.
Outros fatores a serem considerados, como o aumento da população e das famílias beneficiárias, também influenciam a gestão do Programa, embora existam, ainda, lacunas conceituais a serem investigadas, como a relação entre tamanho do município e menor eficiência da gestão, observada na região de estudo. Portanto, é possível concluir pela necessidade, por parte do gestor público, de redirecionar os mecanismos de controle, aprimorar as formas de monitoramento das condicionalidades Saúde e Educação. Uma das alternativas vislumbradas seria a articulação com as outras Secretarias envolvidas no Programa e o aperfeiçoamento do desenho normativo, para que o objetivo do Programa Bolsa Família, que é reduzir a pobreza entre gerações e apoiar as famílias no cumprimento de seus direitos fundamentais, seja, de fato, realizado.

\section{Referências}

BRASIL. Ministério do Planejamento, Orçamento e Gestão. Gestão pública para um Brasil de todos: um plano de gestão para o Governo Lula/Secretaria de Gestão. Brasília, 2003.

BRASIL. Ministério do Desenvolvimento Social e Combate à Fome. Secretaria Nacional de Renda e Cidadania. Análise da pesquisa sobre gestão descentralizada Programa Bolsa Família. Disponível em: <http://www.mds.gov.br/bolsafamilia/menu superior/manuais-e-publicacoes-1>. Acesso em: 27 dez. 2007.

BRASIL. Ministério do Desenvolvimento Social e Combate à Fome. Governo federal regulamenta apoio financeiro aos municípios para gestão do Bolsa Família. Bolsa Família Informa, n. 38. Disponível em: <http://www.mds.gov.br/bolsafamilia/menu superior/informe-pbf/informe-pbf gestores/paginas/ informebolsafamilia_edicao38.htm $>$. Acesso em: 3 jan. 2008a.

BRASIL. Ministério do Desenvolvimento Social e Combate à Fome. 0 papel do gestor municipal do Bolsa Família. Bolsa Família Informa, n. 4. Disponível em: <http://www.mds.gov.br/bolsafamilia/ menu_superior/informe-pbf/informe-pbf-gestores/ paginas/informebolsafamilia_edicaoo4.htm >. Acesso em: 03 jan. 2008b. 
BRASIL. Ministério do Desenvolvimento Social e Combate à Fome. Gestão de benefícios do Programa Bolsa Família. Bolsa Família Informa, n. 7 .

Disponível em: <http://www.mds.gov.br/bolsafamilia/ menu_superior/informe-pbf/informepbf-gestores/ paginas/informebolsafamilia_edicaoo7. htm>.

Acesso em: 3 jan. 20o8c.

BRASIL. Ministério do Desenvolvimento Social e Combate à Fome. Entenda melhor o IGD e a transferência de recursos aos municípios para apoio à gestão. Bolsa Família Informa, n. 41. Disponível em: <http://www.mds.gov.br/bolsafamilia/menu superior/informe-pbf/informe-pbf-gestores/paginas/ informebolsafamilia_edicao41.htm>. Acesso em: 3 jan. $2008 d$.

BRASIL. Ministério do Desenvolvimento Social e Combate à Fome. $O$ índice de gestão descentralizada: mobilização dos gestores municipais do estado de Santa Catarina. Disponível em: <http://sst.sc.gov. br/dias/bolsa_familia/mobil.gestores.cons.Bc/ Apresentacao_Gestao_Compartilhada_SC_20o6-o6o1.ppt>. Acesso em: 3 jan. 20o8e.

BRASIL. Ministério do Desenvolvimento Social e Combate à Fome. Programas do MDS chegam a 6,9 milhões de pessoas em Minas Gerais. Disponível em: <http://www.mds.gov.br/sites/mds-em-numeros/ paginas/minas-gerais>. Acesso em: 11 jan. $2008 f$.

BRESSER-PEREIRA, L. C.; SPINK, P. K. (Orgs.). Reforma do Estado e administração pública gerencial. 7. ed. Rio de Janeiro: Editora FGV, 2006. 314 p.

CASTANHAR, J. C. O que é política pública. Texto base para aulas - Mestrado em Administração Pública. EBAPE/FGV, Rio de Janeiro, [2006].

CHIECHELSKI, P. C. S. Avaliação de programas sociais: abordagem quantitativa e suas limitações. Revista Virtual Textos \& Contextos, Rio Grande do Sul, v. 4, p. 1-12, dez. 2005.

HAIR, J. F. et al. Fundamentos de métodos de pesquisa em administração. Porto Alegre: Bookman, 2005. $471 \mathrm{p}$.

INSTITUTO BRASILEIRO DE GEOGRAFIA E ESTATÍSTICA. Cidade@. Disponível em: < http:// www.ibge.gov.br/cidadesat/default.php>. Acesso em: 20 dez.2007a.
INSTITUTO BRASILEIRO DE GEOGRAFIA E ESTATÍSTICA. Estados@. Disponível em: <http:// www.ibge.gov.br/estadossat/default.php>. Acesso em: 20 dez. 2007 b.

INSTITUTO BRASILEIRO DE GEOGRAFIA E ESTATÍSTICA. Pesquisa Nacional por Amostra de Domicílios - 20o6/IBGE. Disponível em: <http:// www.ibge.gov.br/home/estatistica/populacao/ trabalhoerendimento/pnad20o6/default.shtm>. Acesso em: 28 nov. 2007.

LAVINAS, L. Transferência de renda: o quase tudo do sistema de proteção social brasileiro. Disponível em: <http://www.anpec.org.br/encontro20o6/artigos/ Ao6A157.pdf> Acesso em: 23 nov. 2007.

MAXIMIANO, A. C. A. Introdução à administração. 6. ed. São Paulo: Atlas, 2007. 434 p.

MOREIRA, B. L. Eficiência e eficácia. Disponível em: <http://www.administradores.com.br/artigos/ eficiencia_e_eficacia/361/. Acesso em: 11 mar. 2006.

ORTIZ, L. Descentralização e a municipalização da saúde. Disponível em: <http://www.comciencia. $\mathrm{br} /$ reportagens/ppublicas/ppo6.htm>. Acesso em: 20 dez. 2007.

POCHMANN, M. Política social na periferia do capitalismo: a situação recente no Brasil. Ciência e Saúde Coletiva, Rio de Janeiro, v. 12, n. 6, p. 1477$89,2007$.

RUA, M. G. Análise de políticas públicas: conceitos básicos. Texto base para aulas - Programa de Mestrado em Ciência Política. Brasília: Universidade de Brasília, [2006], 19 p.

TRIOLA, M. F. Introdução à estatística. Rio de Janeiro: LTC, 2005. 656 p.

UNIGUAÇU. Administração pública. Disponível em: <http://www.uniguacu.edu.br/administracao/ admpublica.htm>. Acesso em o3 jan. 2008.

Recebido em: 04/04/2008

Reapresentado em: 05/12/2008

Aprovado em: 28/01/2009 